\title{
Isolation of the Thiobacillus ferrooxidans ntrBC genes using a $T$. ferrooxidans nifH-lacZ fusion
}

\author{
Carol A. Kilkenny, David K. Berger and Douglas E. Rawlings \\ Author for correspondence: Douglas E. Rawlings. Tel: +2721650 3621. Fax: +27 216504023. \\ e-mail: doug@micro.uct.ac.za
}

Department of

Microbiology, University of

Cape Town, Rondebosch

7700 , South Africa

\begin{abstract}
An agar plating technique was developed in which the activation of expression of a Thiobacillus ferrooxidans nifH-lacz gene fusion was used to isolate the ntrBC genes from a $T$. ferrooxidans gene library. An Escherichia coli ntrC mutant containing the nifH-lacz fusion was transformed and plated on a lownitrogen medium so that on flooding with ONPG, the production of yellow colonies indicated the presence of the cloned $T$. ferrooxidans $n t r B C$ genes. A $4.47 \mathrm{~kb}$ region from the $T$. ferrooxidans chromosome was sequenced. Analysis of the sequence revealed that the ntrB and ntrC genes were closely linked to a third ORF of unknown function. Analysis of the $900 \mathrm{bp}$ region upstream of the $T$. ferrooxidans ntrBC genes and Southern hybridization experiments confirmed that in T. ferrooxidans ATCC 33020, the gInA and ntrBC genes are unlinked. Expression of the $T$. ferrooxidans nifH-lacZ fusion in $E$. coli was activated in the presence of the $T$. ferrooxidans ntrBC genes and regulated by nitrogen.
\end{abstract}

Keywords: Thiobacillus ferrooxidans, $n$ tr $B C$ genes, nif $H$-lac $Z$ fusion, nitrogen regulation

\section{INTRODUCTION}

Thiobacillus ferrooxidans is a Gram-negative, diazotrophic, obligately chemolithoautotrophic bacterium that grows optimally in acid ( $\mathrm{pH} 1 \cdot 8-2 \cdot 0)$ conditions. It is usually the dominant member of mixed cultures of bacteria that are used for the commercial recovery of metals such as copper, uranium and more recently gold (Lundgren \& Silver, 1980; van Aswegen et al., 1991). In the highly aerobic conditions of commercial biooxidation tanks, nitrogen fixation is inhibited and nitrogen is added in the form of ammonium sulfate.

Several genes involved in the nitrogen metabolism of $T$. ferrooxidans have been isolated and sequenced. These include the $g \ln A$ (Barros et al., 1985; Rawlings et al., 1987), nifHDK (Pretorius et al., 1987; Rawlings, 1988) and ntr. A (Berger et al., 1990) genes. We wished to isolate other nitrogen genes and regulators as part of an investigation of the nitrogen metabolism of $T$. ferrooxidans. $\mathrm{NtrC}$ (also called $\mathrm{G} \ln \mathrm{G}$ or $\mathrm{NR}_{\mathrm{I}}$ ), the product of the $n \operatorname{tr} C$ gene, is a transcriptional regulator at the heart of the nitrogen regulatory system. In enteric bacteria, NtrC is converted to a transcriptional activator by the binding of a phosphate group to an aspartate residue within the N-

The GenBank accession number for the sequence reported in this paper is L18975. terminal domain (Ninfa \& Magasanik, 1986; Keener \& Kustu, 1988; Sanders et al., 1992). Phosphorylation of $\mathrm{NtrC}$ occurs under nitrogen-limiting conditions and is carried out by $\mathrm{NtrB}$, a member of the histidine kinase family. Under conditions of nitrogen sufficiency, $\mathrm{NtrB}$ acts as a phosphoprotein phosphatase to remove the covalently bound phosphate (Ninfa \& Magasanik, 1986). $\mathrm{NtrB}$ and $\mathrm{NtrC}$ are members of the two-component regulatory systems which respond to environmental stimuli and share strongly conserved domains (Nixon $e t$ al., 1986).

ntr $B C$ genes have been cloned from bacteria by virtue of their linkage to the $g \ln A$ gene (De Bruijn \& Ausubel, 1981; Steglitz-Mörsdorf et al., 1993), through the use of heterologous $n t r C$ probes (Nixon et al., 1986; Szeto et al., 1987) or by complementation of Escherichia coli ntrC mutants for growth on minimal medium with arginine as a sole source of nitrogen (Toukdarian \& Kennedy, 1986). We had previously isolated and sequenced the $g \ln A$ gene from $T$. ferrooxidans (Barros et al., 1985), but there was no equivalent of the $n \operatorname{tr} B C$ genes in the region immediately downstream of $g \ln A$ (Rawlings et al., 1987). We therefore attempted to use the complementation procedure that Toukdarian \& Kennedy (1986) had used to isolate the Azotobacter vinelandii ntrC gene. Our attempts to isolate the $T$. ferrooxidans $n \operatorname{tr} C$ gene by this method were unsuccessful. 


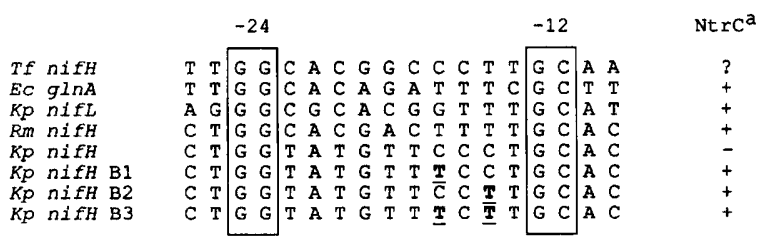

Fig. 1. $\sigma^{54}$-dependent promoter regions of several nitrogen metabolism genes. The conserved -GG- and -GC- doublets at positions equivalent to -24 to -12 from the start site are blocked. NtrCa indicates whether the promoters are activated by NtrC-PO . Bold and underlined letters indicate the $\mathrm{C}$ to $\mathrm{T}$ transitions constructed in the $K$. pneumoniae nifH promoter (Ow et al., 1985). Sequences are those identified by transcript mapping: Ec gInA, E. coli g/nA promoter (Reitzer \& Magasanik, 1985); Kp nifL, $K$. pneumoniae nifL promoter (Drummond et al., 1983); Rm nifH, Rhizobium meliloti nifH promoter (Sundaresan et al., 1983); $K p$ nifH, $K$. pneumoniae nifH promoter (Sundaresan et al., 1983). The $T$. ferrooxidans nifH promoter ( $T f$ nifH) is putative.

A feature of $\mathrm{NtrC}-\mathrm{PO}_{4}$ activated promoters is that they are of the sigma-54 $\left(\sigma^{54}\right)$-dependent type (Popham $e t$ al., 1989). Promoters recognized by the RNA polymerase $\left(\mathrm{E} \sigma^{54}\right)$ holoenzyme are characterized by having $\mathrm{GG}$ and GC doublets at positions -24 and -12 from the transcription start respectively. NifA is an activator of the $\sigma^{54}$-dependent promoters and transcription from the nifH promoter of Klebsiella pneumoniae is normally dependent on the binding of NifA at the upstream activator sequence (UAS). However, transcription from some mutant $K$. pneumoniae nif $\mathrm{H}$ promoters (Ow et al., 1985) may be mediated by $\mathrm{NtrC}$ in the absence of NifA. The sequences in the region between the conserved GG and GC doublets within the $\sigma^{54}$-dependent promoter are important in distinguishing between promoters from which transcription may be mediated by $\mathrm{NtrC}-\mathrm{PO}_{4}$ and those requiring
NifA. Examination of $\sigma^{54}$-dependent promoters (Fig. 1) has indicated that the presence of $T$ residues in positions -17 to -15 is characteristic of a promoter which could be activated by $\mathrm{NtrC}-\mathrm{PO}_{4}$ (Ow \& Ausubel, 1983). In contrast, the wild-type $K$. pneumoniae nif $H$ promoter, which has a stringent requirement not to be activated by $\mathrm{NtrC}-\mathrm{PO}_{4}$, has $\mathrm{C}$ residues at these positions (Benyon $\mathrm{et}$ al., 1983). Ow et al. (1985) used K. pneumoniae nifH-lac $Z$ fusions to study the effect of point mutations in the $K$. pneumoniae nifH promoter region. Three mutant promoters which were the result of $\mathrm{C}$ to $\mathrm{T}$ transitions at positions -17 to -15 (Fig. 1) showed activation by NtrC-PO ${ }_{4}$. Ray et al. (1980) have shown by transcript mapping both in vitro and in vivo that the $K$. pneumoniae nif $H$ B3 promoter mutant (Fig. 1) required $\mathrm{NtrC}-\mathrm{PO}_{4}$ at high intracellular concentration for activation, while NtrC$\mathrm{PO}_{4}$ was unable to activate transcription from the wildtype nifH promoter.

Pretorius et al. (1987) sequenced the nif $H$ gene of $T$. ferrooxidans and reported that it had a $\sigma^{54}$-dependent promoter which in common with $\mathrm{NtrC}-\mathrm{PO}_{4}$ activated promoters, also contained a $T$ at position -15 . In this paper we describe how a $T$. ferrooxidans nif $\mathrm{H}$-lac $Z$ fusion was used to isolate a clone containing the $T$. ferrooxidans $n \operatorname{tr} B C$ genes. We demonstrate through sequencing and Southern hybridization that the $T$. ferrooxidans ntrBC genes are not linked to the $g \ln A$ gene. In addition we show that $T$. ferrooxidans $n t r C$ expression is regulated by nitrogen in an E. coli background.

\section{METHODS}

Bacterial strains, plasmids and media. The relevant properties of the strains and plasmids used in this study are shown in Table 1. Bacteria were grown using Luria broth and glucose minimal medium (GMM) supplemented with nitrogen sources as de-

Table 1. Bacterial strains and plasmids

\begin{tabular}{|c|c|c|}
\hline Strain or plasmid & Relevant characterisics & Source or reference \\
\hline \multicolumn{3}{|l|}{ E. coli } \\
\hline YMC10 & $\Delta l a c U 169$ & Backman et al. (1981) \\
\hline ET 8556 & ntrC1488 lacZ: :IS1 gyr $A$ rbs but $C_{K}^{c}$ & Merrick (1983) \\
\hline ET8051 & $\Delta(r b a-g \ln A) g y r A r b s b u t C_{K}^{c}$ & Pahel \& Tyler (1979) \\
\hline \multicolumn{3}{|l|}{ Plasmids } \\
\hline pEcoR252 & $\mathrm{Ap}^{\mathrm{r}}$ EcoRI & P. Janssen, Ghent \\
\hline pBluescript $\mathrm{SK}^{+}$ & $A p^{r}$ & Stratagene, San Diego \\
\hline $\mathrm{p} A C Y C 184$ & $\mathrm{Cm}^{r} \mathrm{Tc}^{r}$ & \\
\hline pHC79 & $A p^{r} T c^{r}$ cosmid vector & Hohn \& Collins (1980) \\
\hline p'T101 & $\mathrm{Ap}^{\mathrm{r}} T$. ferrooxidans genomic fragment in vector $\mathrm{pHC} 79$ & This work \\
\hline $\mathrm{pH} l a c$ & $\mathrm{Ap}^{\mathrm{r}} \mathrm{T}$. ferrooxidans nif $\mathrm{H}-\mathrm{lac} Z$ in vector $\mathrm{pMC} 1403$ & Berger et al. (1990) \\
\hline $\mathrm{pH} / a c 10$ & $\mathrm{Cm}^{\mathrm{r}}$ T. ferrooxidans nif $\mathrm{H}-\mathrm{lac} Z$ in $\mathrm{Tc}^{r}$ gene of $\mathrm{pACYC} 184$ & This work \\
\hline $\mathrm{pH} / \mathrm{ac} 20$ & $\mathrm{Cm}^{\mathrm{r}} \mathrm{pH}$ lac 10 but $\mathrm{Tc}^{\mathrm{r}}$ promoter deleted & This work \\
\hline $\mathrm{pK} 70$ & $\begin{array}{l}\mathrm{Ap}^{\mathrm{r}} K . \text { pneumoniae } g \ln A^{+} n t r B^{+} n t r C^{+}, \text {HindIII fragment of } \mathrm{pFB} 514 \\
\text { cloned into HindIII site of } \mathrm{pHC} 79\end{array}$ & This work \\
\hline pFB514 & $\mathrm{Cm}^{\mathbf{r}} \mathrm{K}$. pneumoniae gln $A^{+} n \operatorname{tr} B^{+} n \operatorname{tr} C^{+}$ & De Bruijn \& Ausubel (1981) \\
\hline $\mathrm{p} 804$ & Ap $^{r}$ E. coli $n t r B^{+} n \operatorname{tr} C^{+}$ & Tuli et al. (1982) \\
\hline pMEB100 & $\mathrm{Ap}^{\mathbf{r}} T$. ferrooxidans $g \ln A^{+}$ & Barros et al. (1985) \\
\hline
\end{tabular}


Table 2. Expression of the T. ferrooxidans nifH-lacZ fusion in $E$. coli in the presence and absence of $n t r C$ genes

\begin{tabular}{|c|c|c|}
\hline Strain and relevant genotype* & \multicolumn{2}{|c|}{$\begin{array}{c}\beta \text {-Galactosidase activity } \\
\text { (Miller units) }\end{array}$} \\
\hline YMC10 ntrBC ${ }^{+}(\mathrm{pH} l a c)$ Tf nifH-lacZ & \multicolumn{2}{|c|}{$32024 \dagger(4220)$} \\
\hline ET8556 ntrC (pHlac) Tf nifH-lacZ & \multicolumn{2}{|c|}{$214+(38)$} \\
\hline ET8556 ntrC (pFB514, $\mathrm{pH}$ lac) Kp ntrBC $C^{+}$, Tf nifH-lacZ & \multicolumn{2}{|c|}{$13326 \dagger(1952)$} \\
\hline & Low $N \ddagger$ & High $\mathrm{N} \ddagger$ \\
\hline ET8556 ntrC (pHlac20, pHC79) Tf nifH-lacZ & $312(26)$ & $266(42)$ \\
\hline ET8556 ntrC (pT101, pHlac20) Tf ntrBC + , Tf nifH-lacZ & $1048(125)$ & $553(74)$ \\
\hline ET8556 ntrC (pT130, pHlac20) Tf ntrBC $C^{+}$, Tf nifH-lacZ & $2035(420)$ & $483(65)$ \\
\hline ET8556 ntrC (pHlac20) Tf nifH-lacZ & $654(77)$ & $413(58)$ \\
\hline ET8556 ntrC (pK70, pHlac20) Kp ntrBC ${ }^{+}$, Tf nifH-lacZ & $2185(415)$ & $452(61)$ \\
\hline YMC10 ntrBC ${ }^{+}(\mathrm{pHC} 79, \mathrm{pH} l a c 20)$ Tf nifH-lac $\mathrm{Z}$ & $7634(1015)$ & $464(62)$ \\
\hline ET8051 ntrBC (pHlac20) Tf nifH-lacZ & $341(49)$ & $418(55)$ \\
\hline ET8051 ntrBC (pT130, pHlac20) Tf ntrBC ${ }^{+}$, Tf nifH-lacZ & $1252(325)$ & $980(157)$ \\
\hline ET8051 ntrBC (p804, pHlac20) Ec ntrBC ${ }^{+}$, Tf nifH-lacZ & $2816(633)$ & 1577 (139) \\
\hline
\end{tabular}

* Tf, $T$. ferrooxidans; Ec, E. coli; Kp, Klebsiella pneumoniae; host genotype follows strain designation, plasmid genotype follows plasmid name.

† Strains were grown aerobically under nitrogen-limiting conditions.

‡ Strains were grown in GMM supplemented with either low-nitrogen (Low N) or high-nitrogen (High $N$ ) as described in Methods. $\beta$-Galactosidase data are the means of three assays, with standard deviations in parentheses.

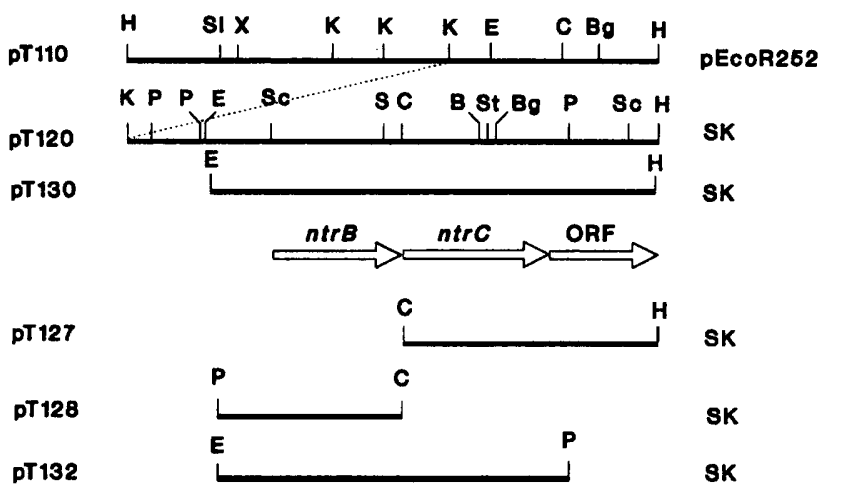

Fig. 2. Restriction endonuclease map of the $13.2 \mathrm{~kb}$ HindIII $T$. ferrooxidans chromosomal DNA insert of construct pT110 and derivatives. The $n \operatorname{tr} B$ gene, ntrC gene and ORF of unknown function as well as the direction of transcription are indicated by the open arrows. pEcoR252 and SK are the cloning vectors pEcoR252 and pBluescript $\mathrm{SK}^{+}$respectively. $\mathrm{B}, \mathrm{BamHI} ; \mathrm{Bg}, \mathrm{Bg} / \mathrm{II}$; C, Clal; E, EcoRl; H, HindllI; K, Kpnl; P, Pstl; S, Sall; Sc, Sacll; SI, Sacl; St, Stul; X, Xhol.

scribed. When required, antibiotics were added at the following concentrations: ampicillin, $100 \mu \mathrm{g} \mathrm{ml}^{-1}$; chloramphenicol, $25 \mu \mathrm{g} \mathrm{ml}^{-1}$; tetracycline, $20 \mu \mathrm{g} \mathrm{ml}^{-1}$.

DNA techniques, sequencing and analysis. The alkaline lysis method was used for both small- and large-scale DNA preparation. Standard methods (Sambrook et al., 1989) were used for restriction digests, gel electrophoresis, ligations and Southern blot hybridizations. Probes used in hybridization experiments were labelled by nick-translation using the DIG system (Boehringer Mannheim). DNA sequencing was carried out by the dideoxy-chain-termination method with overlapping templates generated by exonuclease III shortening. Where templates failed to overlap, custom-made single-stranded sequencing primers were used. Sequencing reactions were carried out by using the Sequenase kit (version 2.0) from US Biochemical. The entire sequence reported in Fig. 3 was determined from both strands. The DNA sequences were analyzed with the Genepro (version 4.1) program and the Genetics Computer Group Inc. software package (version 7.1).

Plasmid constructions. The construction of the $T$. ferrooxidans nif $\mathrm{H}$-lac $\mathrm{Z}$ fusion plasmid, $\mathrm{pH}$ lac, has been described previously (Berger et al., 1990). This plasmid contains the pMC1403 vector, while the cosmid gene library that was screened was based on the vector $\mathrm{pHC79}$. Both vectors contain the same pBR322derived replicon and ampicillin-resistance marker. The $T$. ferrooxidans nif $H$-lac $Z$ fusion was therefore subcloned into the compatible pACYC184 vector as follows. An $8.4 \mathrm{~kb}$ EcoRI-SalI fragment from $\mathrm{pH} l a c$ (containing the $T$. ferrooxidans nifH-lac $Z$ fusion and the lac $Y A$ genes) was ligated to $\mathrm{pACYC184}$ that had been digested with BamHI and SalI. After ligation of the SalI ends, the remaining EcoRI and $B a m \mathrm{HI}$ ends were filled-in with the Klenow fragment of DNA polymerase and these blunt ends ligated. This gave plasmid pHlac10, containing a pBR322compatible pACYC184 replicon and a chloramphenicol-resistance marker. As the T. ferrooxidans nifH-lac $Z$ fusion had been cloned into the pACYC184 tetracycline-resistance gene behind its promoter, this promoter was deleted by digestion of $\mathrm{pH} l a c 10$ with $\mathrm{XbaI}$ and EcoRV (both unique sites upstream and downstream of the tet promoter), the $X b a I$ sticky end was filled in and the flushed ends ligated to give plasmid $\mathrm{pH} l a c 20$.

Development of a screening technique and the isolation of the ntrC gene. An agar plate medium was developed whereby it was possible to distinguish single E. coli colonies which exhibited low-level expression of the T. ferrooxidans nif $\mathrm{H}-\mathrm{lac} Z$ fusion from those that exhibited high-level expression. Several media were tried before a successful medium and procedure was 
CTGCAGGCTGTTGGCGCGGTAAATGAGCAGTTCCACCGGAGACCTACGGI:GACATTGCTGCGCATGGTGGAATTCATGGAGACCAGCGCACAGCGTGCCG CAGCCTCCAGCGAGAGGTCGGGCCTGACTACGCGGTCCAGGATCGGTTTGCCGTACTTGATTTCGCCGATTTGCAGAAAGGATGGTCCGACGATTCATG GATATAGTTGCCTTGTGGATAGATCATATAGGTGGCTGGCATCTCTGCCCCGATCTGCCCACCGAGTATGAAGGTCGCCTCGAAATTGGTGTTGGCGGTA TCGCGGTTGGCTTGGTTGCGCTGCACCTCGGCATTGATGAGGCCGACATAATCCGCCGCCTCCGCCATGCTGCCCAGATTGAGCAGATGGATTTCGGCGT CCTGGTCGATATCTTGCTGCATCCGCTTGACCACGCCCTGGGTGGTCGCCAGATTGCCCGCTGAAAGCAGGCAGAGAAAACGATCCCCGGGCCAGCAGAA GTGATGCATTTTCGAGTAGATGCTGACATTGTCGGTGCCCGCGTTGGTCCGCGAGTCTGAGCAGAAAACCAGACCCCCGGTGACGTGGGTGGTGAGGCAA TAGGTCATGGAGTATTCCTGTGAGCCCGACGACATGGATGGATGATAGTCGTCCGAAAATACCGTCCTTGGGAAGCCCGACCAAGAGGTCGCTCGGCAAT GTGCGCTAGGCGCTCGTCCATAATGCACTATTATGGTGCATCATATGCGTCTGCACCGGCTGCCGCACGATAAGGGCATGCCTGGTGTTTGCGTCGGGG

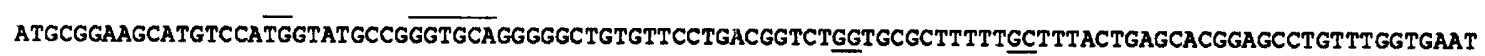
CATAAGATCGGACTTGCATGGCGCGCCGCAAAACATAACCACCCTGCCCGCGGAGAATATGGTGCTGGACGCCCTGGAATCAGCGGTACTGGTTCTGG $\begin{array}{llllllllllllllllllllllllllllll}M & A & R & R & K & N & I & T & T & L & P & A & E & N & M & V & I & D & A & \text { L } & E & S & A & V & L & V & \text { I } & G\end{array}$

$\begin{array}{lllllllllllllllllllllllllllllllllllll}M & Q & D & R & I & Y & G & A & A & Q & E & M & \text { L } & R & G & \text { I } & \text { A } & \text { H } & \text { E } & \text { I } & K & \text { N } & \text { P } & \text { L } & G & G & \text { I } & R & G & A & A & Q & L & 161\end{array}$ CCTGGATCGCGAGTTGCAACGCCCGGAACTGAAAGATTACACCCGCGTCATTCTCCATGAGGTGGATCGTCTGCATCATCTGGTGGATCGCCTCCAGGGA 1500

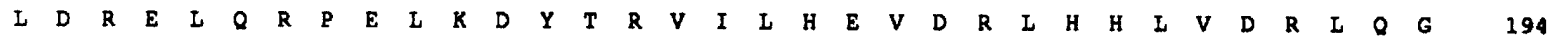
CCCCGTAGCCGCCCGGTTTTTGCCGAGGTGAATATCCATCAGGTGCTGGAGCACGTGCGTCGTCTGCTGAATGCGGAATTGCCCACCGGTATTGCCGTGC 1600 $\begin{array}{lllllllllllllllllllllllllllllllllllllll}P & R & S & R & P & V & F & A & E & V & N & I & H & Q & V & L & E & H & V & R & R & I & I & N & A & E & I & P & T & G & I & A & V & R & 228\end{array}$

GTTTCGACTACGACCCCTCCATTCCCGACCTTATGGCGGACCAGGAGCAACTGGTGCAAGTTTTTCTGAATCTGATGCGCAATGCCCAACAGGCGCTGGA 1700

$\begin{array}{llllllllllllllllllllllllllllllllllll}F & D & Y & D & P & S & I & P & D & \text { L } & M & A & D & Q & \text { E } & Q & \text { L } & \text { V } & Q & \text { V } & \text { F } & \text { L } & \text { N } & \text { L } & \text { M } & \text { R } & \text { N } & \text { A } & Q & Q & \text { A } & \text { L } & \text { D } & 361\end{array}$ CCGCCACGGTGCAATTCTGATCCGTACCCGGGTCGAACGCTACGTTACCCTGCTGCACCACAAGTTCCGCCTGGCGCTGCGTGTGGATGTAGTCGACAAC 1800

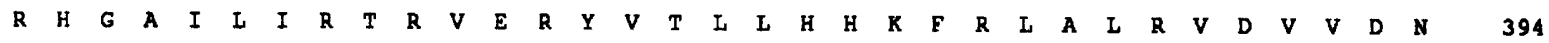
GGCCCGGGAATCTCCCCGGATCTGCTGCCACGGATCTTTTTGCCCCTGGTCACCAGTCGTGCCGAGGGTATGGGAATGGGGCTCGCCATCGTACAGGGAC 1900 $\begin{array}{lllllllllllllllllllllllllllllllllllll}G & P & G & I & S & P & D & L & L & P & R & I & F & \text { L } & \text { P } & \text { L } & \text { V } & \text { T } & \text { S } & R & A & E & G & M & G & M & G & \text { L } & \text { A } & \text { I } & \text { V } & Q & G & \text { L } & 428\end{array}$ TGGTGCGCGGGCATGGCGGCGTGGTCCACTGCCATTCACAACCGGGAGAAACGGTATTTTCCGTTTCTCTGCCCCTGTCACCGCACCGOGACOCATCCGC 2000

$\begin{array}{llllllllllllllllllllllllllllllllllll}V & R & G & H & G & G & V & V & H & C & H & S & Q & P & G & E & T & V & F & S & V & S & \text { L } & \text { P } & \text { I } & S & P & H & R & E & A & S & A & 461\end{array}$ ATGACACAAGTCTGGATTATCGATGACGACCCTTCCATTCGCTGGGTTTTGGAGAGGCGTTGACTCAGGCCGATATCCTGGTGCGCAGCTTTGCAGACG 2100 *

$\begin{array}{lllllllllllllllllllllllllllllllllllll}M & T & Q & V & W & I & I & D & D & D & P & S & I & R & W & V & I & E & K & A & I & T & Q & A & D & I & L & V & R & S & F & A & D & A\end{array}$ CCGACAGCGCGCTGCGGGCTTGGGGCGTGAGCAGCCAGGGGCCGTTGTCACCGATCTGCGTATGCCCGGCCTGGACGGATTGGCGTTTCTGCGCGAAGT

$\begin{array}{llllllllllllllllllllllllllllllllllllll}D & S & A & L & R & A & L & G & R & E & Q & P & G & A & V & V & T & D & L & R & M & \text { P } & G & \text { L } & D & G & \text { L } & A & F & L & R & E & V & & 67\end{array}$ TCAGTCGCGCTGGCCAAAACTGCCGGTGATCGTGATGACGGCGCACTCT GATCTCGACAATGCCGTCGCCGCTTTTCAAAGTGGGGCCTTTGAGTATCTG 2300 $\begin{array}{llllllllllllllllllllllllllllllllllll}\text { Q } & \text { S } & \text { R } & \text { W } & \text { P } & \text { K } & \text { L } & \text { P } & \text { V } & \text { I } & \text { V } & \text { M } & \text { T } & \text { A } & \text { H } & \text { S } & \text { D } & \text { L } & \text { D } & \text { N } & \text { A } & \text { V } & \text { A } & \text { A } & \text { F } & \text { Q } & \text { S } & G & \text { A } & \text { F } & \text { E } & \text { Y } & \text { L } & & 100\end{array}$ CCCAAGCCGTTTGACATGGACGAGGCGGTTACGCTGGTGCAGCGCGCCCTCGGCAGCCGGGCTGGACCGGGCGCGGGGGTGTGGAGGAGAGCGATCCGG 2400 $\begin{array}{llllllllllllllllllllllllllllllllllllll}\text { P } & \text { K } & \text { P } & \text { F } & \text { D } & \text { M } & \text { D } & \text { E } & \text { A } & \text { V } & \text { T } & \text { L } & \text { V } & \text { Q } & \text { R } & \text { A } & \text { I } & G & \text { S } & \text { R } & \text { A } & G & \text { P } & G & \text { A } & \text { A } & G & \text { V } & \text { E } & \text { E } & \text { S } & \text { D } & \text { P } & \text { A } & 134\end{array}$ CGGAAATGATCGGTGAGGCTCCGGCCATGCAAGAGGTGTTTCGTGCCATCGGGCGTCTGTCGCGCTCACAGATCAATGTGCTGATTACCGGCGAATCGGG 2500

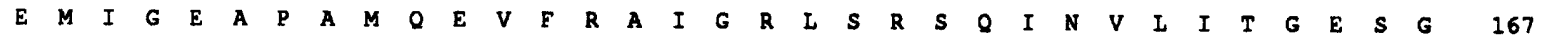
ATCCGGCAAGGAACTGGTGGCCAGTGCACTGCACCGGCACAGCCCCCGTGCGCGCGGACCTTTCATTGCCATCAACACGGCGGCCATTCCCGCCGAGTTG 2600 $\begin{array}{lllllllllllllllllllllllllllllllllllll}S & G & \text { K } & \text { E } & \text { L } & \text { V } & \text { A } & \text { S } & \text { A } & \text { L } & \text { H } & \text { R } & \text { H } & \text { S } & \text { P } & \text { R } & \text { A } & \text { R } & \text { G } & \text { P } & \text { F } & \text { I } & \text { A } & \text { I } & \text { N } & \text { T } & \text { A } & \text { A } & \text { I } & \text { P } & \text { A } & \text { E } & \text { L } & & 200\end{array}$ CTGGAATCGGAACTTTTCGGCCATGAAAAGGGCGCTTTTACCGGGGCGGTGCAGACTCGGCAGGGGCGCTTCGAGCAGGCCTCCGGGGAACCCTCTTTC 2700

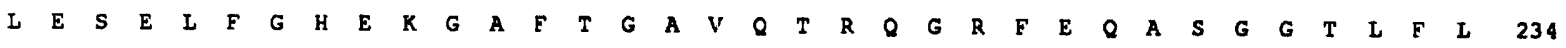
TGGATGAATCGGCGATATGCCGGCCGCCCTGCAAACGCGCCTGCTGCGGGTGCTTTCCGACGGCACTTTCTATCGGGTCGGTGGCCACGCGCCCCAGCG 2800

$\begin{array}{lllllllllllllllllllllllllllllllllll}D & E & I & G & D & M & P & A & A & \text { L } & Q & T & R & \text { L } & L & R & V & \text { L } & S & D & G & T & F & Y & R & V & G & G & H & A & P & Q & R & 267\end{array}$ TGCGGACGTCCGCGTCCTCGCCGCGACCCACCAGAACCTCGAAGCCAAGGTGCGCGATGGCAGCTTCCGGGAAGATCTCTACCACCGTCTCAACGTCATC 2900

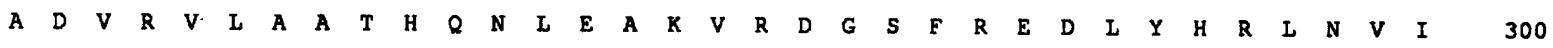
CATATCCATCTTCCGCCCATACGCGAGCGGCGTGAGGACATTCCGCGTCTGGCCCGCCATTTTCTCCGTCGTAGCGCGGAGCAACTGGATGTCGAGCGGC 3000

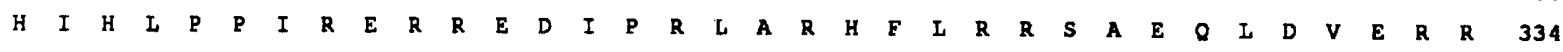
GAATATTGAGCCCGGAGCGAGTCGCCTTCATGAACTGGCATTGGCCCGGCAATGTGCGCCAATTGGAAAACGTCTGTCGCTGGATTACGGTGATGGCACC 3100

$\begin{array}{llllllllllllllllllllllllllllllllllllll}I & L & S & P & E & R & V & A & F & M & N & W & H & W & P & G & N & V & R & Q & \text { L } & E & N & V & C & R & W & I & T & V & M & A & P & 367\end{array}$

Fig. 3. For legend see facing page. 
$\begin{array}{llllllllllllllllllllllllllllllllllllll}T & R & E & V & Q & \text { V } & \text { T } & \text { D } & \text { I } & \text { P } & \text { P } & \text { E } & \text { M } & \text { A } & \text { A } & \text { S } & \text { P } & \text { M } & \text { S } & \text { A } & \text { M } & \text { M } & \text { P } & \text { D } & \text { P } & \text { N } & \text { T } & \text { Q } & \text { D } & \text { W } & \text { R } & \text { L } & \text { L } & 400\end{array}$ CTGGGGGCGGTGGTGCGGCACGTCTCGCGGCGTGAAGAAGCCTTGCTGGACAAGATTCAGCCGCTGTTCGAACGCTGTCTGCTGGAAGCGGCCCTGCAAC 3300

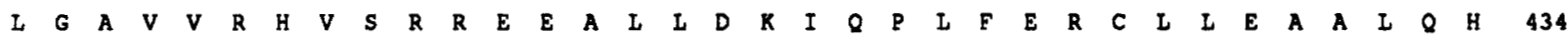
ATACCCGTGGCCATAAGCAGAGCGCCGCGCACAAACTCGGGTGGGGGCGCAATACGCTCACCCGCAAGCTGAAAGAGTTGGGCATGGCGGAGGATACGTA 3400

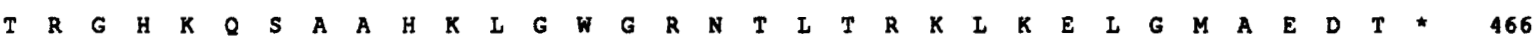
AGGCGTCGGTTCTGGCGATCCCGGGCTTTCGACTAAAACCCCCTTGTATGTGGTTATAAAGGGTATGCTTGGTCGCGCTTGGGGTGTCTATGCAAGGTG 3500 TAATGTTACTGTTGGAAATCGTTGTCGTCCTGCTGCTACTGGTGGAGGTTTTCATTCGTCTGAGGGCACGGCGCCGCCGTTTACAGAACAAAAGCAGCGC 3600

$\begin{array}{lllllllllllllllllllllllllllllllllllll}M & \text { L } & \text { L } & \text { L } & \text { E } & \text { I } & \text { V } & \text { V } & \text { V } & \text { L } & \text { L } & \text { I } & \text { L } & \text { V } & \text { E } & \text { V } & \text { F } & \text { I } & R & \text { L } & R & \text { A } & R & R & R & R & \text { L } & 0 & \text { N } & K & S & S & A & & 37\end{array}$ GCCAGTCTCCTCAGCAGCGCGTTCGGCACCCGCCACAGACGTGCTGCAGATTCGACCCGAAGTGTCCGGCGTAAATGCTGTTGTCCCACCCGTAACCACT 3700

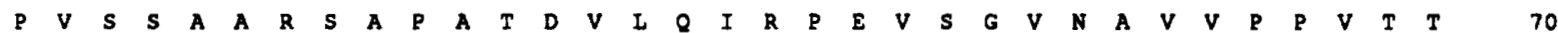
ACCGGTGGCGCCGAGCAGCAAGCGCTCAGCATTGACGACCTCCTCAATGAAGCGACCATTTACCTGGAGTATGGCCACTATGCGCAGGCCGCGACCGTGT 3800

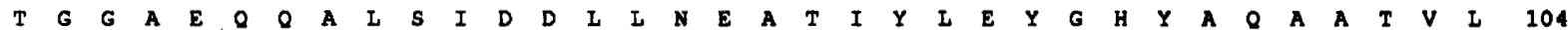
TGCGCTGGTATGTGGATATCAACCCGCATGTGACCAAACCCATCAACATGCTCCTGGATGCCTATCTTGCCATGGCCGATATCGACAGCTATGCCGACCT 3900

$\begin{array}{lllllllllllllllllllllllllllllllllllll}R & \text { W } & \text { Y } & \text { V } & \text { D } & \text { I } & \text { N } & \text { P } & \text { H } & \text { V } & \text { T } & \text { K } & \text { P } & \text { I } & \text { N } & \text { M } & \text { L } & \text { L } & \text { D } & \text { A } & \text { Y } & \text { I } & \text { A } & \text { M } & \text { A } & \text { D } & \text { I } & \text { D } & \text { S } & \text { Y } & \text { A } & \text { D } & \text { L } & 137\end{array}$ GCTCGAAAGTCTGGGAGAAAAGCCGGGGGCTGCCCCCATGGACGAGTCCTGGTGGCGGGAACGGGTAAATACCGGTCTGAGTCAGGATCCCGGCAATCTT 4000 $\begin{array}{lllllllllllllllllllllllllllllllllllll}\text { L } & E & S & L & G & E & K & P & G & A & A & P & M & D & E & S & W & W & R & E & R & V & N & T & G & \text { L } & S & Q & D & P & G & N & I & & 170\end{array}$ GAACTCCTCGTGCTTGCCGAGAAAGTGGCATGGCCATCCCTCTTCCGCAAGTGCGAACTCCGGATGCCGTCATGACCGCGGAGATGGCGCTGGCCCTGG 4100

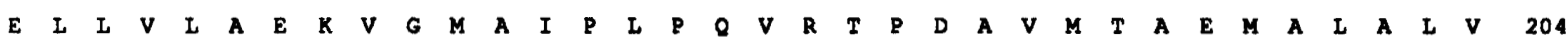
TGTCCCGCAACCACGATCCGGCCTACGGCATGGCGATCCTGTGGCGGGCTATCGCCCATGAACCGCGGCGACTGCCGTTGTATGCCGAACTTCTGCGCAT 4200 $\begin{array}{lllllllllllllllllllllllllllllllllllll}S & R & N & H & D & P & A & Y & G & M & A & I & \text { L } & \text { W } & R & \text { A } & \text { I } & \text { A } & \text { H } & \text { E } & \text { P } & R & R & \text { I } & \text { P } & \text { L } & \text { Y } & \text { A } & \text { E } & \text { L } & \text { I } & R & \text { I } & 237\end{array}$ AACCTACCAGCAACGCCGTATCGAGGATTATATCAATACCCTGATTCTGCTCTTCCTGGCGGTGGGCAGTGGTGGCAAAACCTTGCGTGAACGCATGTTG 4300

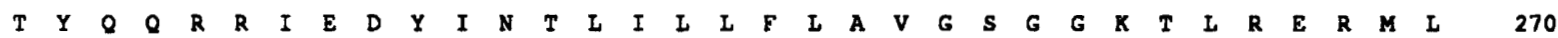
CGGGCAGGTGAAGACCTCGGCCCGCACCTCCTGTGGGATACCCTTGCACAATGGAATGGCGACCCGGAAGTATTGAGACGATTGGCCAGATCACGCCAAC 4400

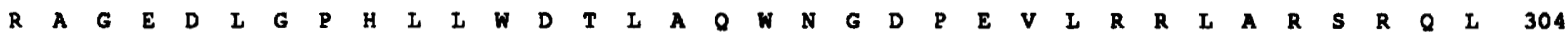
TGGAGATTCCGGTCGGGTTGTCCGGCGCTGCGGCACAAGGCGGATGACCGCGCTTGACAAGCTTATCGAT

Fig. 3. Nucleotide sequence of the $4.47 \mathrm{~kb}$ EcoRl-Hindlll fragment containing $T$. ferrooxidans $n \operatorname{tr} B$, ntrC and the unidentified ORF. Predictd amino acid sequences are given below in single-letter code. Putative ribosome-binding sites are indicated in bold, the putative $\sigma^{54}$ promoter is underlined and potential NtrC-binding sites are overlined.

developed. The optimal procedure was to plate transformed or

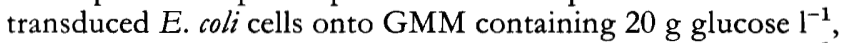
$0.02 \%$ Casamino acis, $0.2 \%$ yeast extract and $16 \mathrm{~g}_{\text {agar }} \mathrm{l}^{-1}$. Plates were incubated for $48 \mathrm{~h}$ at $37^{\circ} \mathrm{C}$, cooled to $4{ }^{\circ} \mathrm{C}$ and then flooded with $2 \mathrm{ml} \mathrm{ONPG}\left(4 \mathrm{mg} \mathrm{ml}^{-1}\right)$. E. coli YMC10(pHlac10 or 20) and E. coli ET8556(pHlac10, pK70) colonies which contained either the $E$. coli or $K$. pneumoniae ntr $C$ gene produced bright yellow colonies within 5-15 min. A problem with colony wash-off on flooding with ONPG was experienced initially. Incubation at $4{ }^{\circ} \mathrm{C}$ to 'harden' the colonies solved the problem of colony dislodgement. The addition of the chromogenic dye 5-bromo-4-chloro-indolyl $\beta$-D-galactopyranoside (X-Gal) instead of ONPG to the medium was too sensitive and most colonies turned blue. MacConkey/lactose medium contained too high a concentration of undefined nitrogen sources to be workable.

Protein gels. Translation products were identified by using a prokaryotic DNA-directed transcription-translation kit (E. coli S30 System, Promega). Polypeptides were separated on sodium dodecyl sulfate (SDS)-12\% (w/v) polyacrylamide gels.

$\boldsymbol{\beta}$-Galactosidase assays. E. coli cells containing the $\mathrm{pH}$ lac or $\mathrm{pH}$ lac 20 fusion constructs were transformed with the test plasmid. Cells were grown in a preculture as described above and inoculated at an $\mathrm{OD}_{600}$ of $0 \cdot 2$ units into the assay culture media. To assay $\beta$-galactosidase activity in nitrogen-rich media, GMM supplemented with (w/v) $0.2 \%$ glutamine, $0.2 \%$ $\left(\mathrm{NH}_{4}\right)_{2} \mathrm{SO}_{4}, 0.2 \%$ Casamino acids and $0.2 \%$ yeast extract was used. Nitrogen-poor medium consisted of GNM containing (w/v) $0.02 \%$ glutamine, $0.02 \%$ Casamino acids and $0.02 \%$ yeast extract. Appropriate antibiotic selection was provided at all times and cultures were grown in their respective media for at least $4 \mathrm{~h}$ before $\beta$-galactosidase assay.

\section{RESULTS}

\section{Cloning of the $T$. ferrooxidans ntrC gene by activation of expression of a $T$. ferrooxidans nifH-lacZ fusion}

In order to test the isolation strategy, experiments were carried out to determine whether there was an increase in expression from the $T$. ferrooxidans nif $H$ promoter in the presence of a cloned $K$. pneumoniae ntr $C$ gene. The $E$. coli ntrC mutant ET8556 containing the $T$. ferrooxidans nifH-lac $\mathrm{Z}$ fusion plasmid, $\mathrm{pH}$ lac, produced low basal levels of $\beta$-galactosidase activity when grown in nitrogen- 
(a) $\mathrm{Tf}$

Kp
Va
Pv

$\mathrm{Pv}$

$\mathrm{Bp}$

Ab

Tf

Ec

Kp
Va
Pv

EC

Vp

Tf ASA

BP ATRPQKPR

Ab MSGDPAPARGIRGAIG
MARRKNIT . TLP. . AENMVLDALESAVL VLGADYH IRYMNPAAENLLRSASTRHWGNICRRCAASLAKSDLPHFSWI PSRRTR MATGT'QPDAGQ . . ILNSLINSI ILIDDNLA IHYANPAAQQLL . AQSSRKLFGT PLPELLSYF . S. LN I ELMQESLEAG MATGTLPDAGQ . . ILNSL INS ILLVDDDLAVHYANPAAQQLL . AQSSRKLFGTPLPELLSYF . S. LN IGLMQESLAAG MVTATLI ILDGLAIRYANPAAELLF. SQSAKRIVEQSI,SQLIQHA.S. LDLALLTQPLQSG METGNLP. . DNTLILDSLIHSVL IINQEF I I CYANHAALQVL. AQSRRKLFETPFTDLFSYH . S. FDAELMQETLANG MTSAMEFRRPVPTDGEA ILNALPNPVL VAPDGR IVDANI AAESFF. EISTQFLRRQSLKELVPFG . SPLLALIEQVRTSG . MNLPP. . PGI IWNSLPLPAL ILDVNDRVIEINPAAELFL. NLSARALKGQALGERLAI . . SAPLEE I FARVRKN.

$$
\text { L }
$$

N AA S

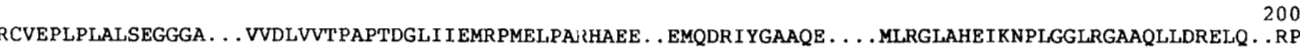
QGFTDNEVTLVIDGRSH . . . ILSVTAQRMPDGMILLEMAPMDNQRILLSQE . . QLQHAQQVAARD . . . . . LVRGLAHE I KNPLGGLRGAAQLLSKALP . . DP

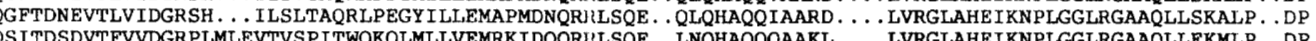

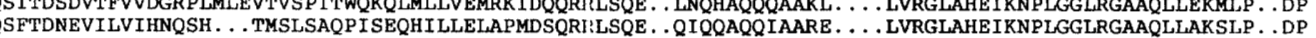
SPV. NEYKVDLGTPR I . . GGDRQVDLHVAPLTERPGH IVVML QEFTT IADKMDRQLTHRSAARS. VIALAAMLAHE IKNPLSGIRGAAQLLEQQASSEDR . RSALFVNDVDL. TTGE . RAPVQCNLQAAPIADDPETVLLLI SPE!E IADRLGRASMVKSAARSAGIGMAEMLAAHEI KNPLAGIAGAAQLLSMGLSGEDL HRASQEG . VVID . TTAH . RPAPCHRAGTPRWASP PTMCMLTVNEY:TLARK IDNSLTHRNAARS . VTAMASMLGHEVKNPLSG IRGAAQLLEENCSSESDR AA LAHEIKNPL G RGAAQLL,

300

KDYTRVIILHEVDRLHHLVDRL . QGPRSR PVFAEVN IHQVLEHT RRLLNAELPTGIAVRFDYDPSIPDLMADOEQLVQVFLNLMRNAQQALDRHGA. . SLLEYTKVI I EQADRLRNLVDRL . . LGPQLPGTRVTESIHKVAERV VTLVSMELPDNVRL IRDYDPSLPEIAHDPDQI EQVLLNIVRNALQALGPEGGE . ALMEYTKVI IEQADRLRNLVDRL . . LGPQHPGMHVTES I HKVAERVVKLVSMELPDNVK LVRDYDPSLPELPHDPDQI EQVLLNI VRNALQQALGPEGGE. ATEYTOVI IEAODRLRTLVRL . . LGPQRPGKKTQENLHQI LEKVRQLVELESQRS IVIERDYDPSLPEILADADQIEQAMLNIVSNAAQILSHQEHGK LLTR . . LICDRADR IVTLVDRMEVFGDDRPVARGPVNIHSVLDHVKRLAQSGFARNVRF I EDYDPSL.P PVLANQDQLIQVFLNLVKNAAEAVADLGTDA ELTD . . . LIVDETRR IVKLLEOVEOFGNVRPPEMKPVN I HDVLDRARKSAGVGFGAHML IVEDYDPSVP PTLGDADQLTQVFLNLLLKNASEAAKGOGT . . LTR. RLICDEADR IVALVNRMEVFSDORP PERDAVNIHTVLEHVRKVAQSGFARNIRFI ERYDPSLPPVYGNRDOLIOI FLNLI KNAAEAAPESGGE

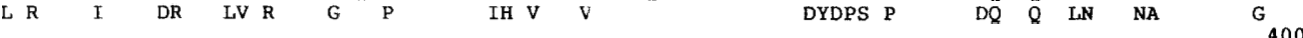
LIRTRVERYVTL . . . . . . LHHKFRLALRVDVVDNGPGISPDLLPRI FLPI,VTSRAEGMGMGLAIVQGLVRGHGGVVHCHSQPGETVFSVSLPLSPHRE ILRTRTAFQLTL . . . . . . . HGERYRLAAR I DVEDNGPGI PPHLQD ILFY PMVSGREGGTGLGLS I ARNLIDQHSGK IEFTSWPGHTEFSVYLP IRK TLRTRTAFQLTL $\ldots \ldots \ldots$ HGVRYRLAAR I DVEDNGPGI PSHLQD FLFY PMVSGREGGTGLGLSIARSLIDQHSGKIE FTSWPGHTEFSVYLPIRK ITRTRTVHQANI $\ldots \ldots \ldots$. . . HGKR CKLAARVE ITDNGPGI PPELQD ILFYPMVSGREGGTGLGLSISQNLIDQHNGK IDVESWPGHTPFTIYLP I IRTRTAFOITL . . . . . HGERHRLVAR IDVIDTGSGI PPHLQD TLFY PMVSGREDGNGLGLSAIRNLVDOHAGR I EFTSWPGNTEFS I YLPIR ELTTAFR PGV. . RLSVPGKK SRVSLPLEFCVKDNGSGVPEDLLP VLFDPFVTTKOYGSGLGLALVAR IVGDHGGIIECESOPRKTTFRVLDADVQRRQ RLRTFYDYALRLRRPDGGGERCAAAPLQVEVIDDGPGI PADIAS 3 IFEPFVSGRENGTGLGLALVSR I ISEHNGWI SVESAPGRTLFR I SLPVAPKEL . RLRTFYDYALRLRRPDGGGERCAAAPLQVEVIDDGPG I PADIAS S IFEPFVSGRENGTGLGLALVSK I ISEHNGWISVESAPGRTLFR I SLPVAPKEL

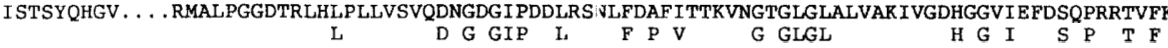

$$
\text { L D G GIP I. F P V G GLGL }
$$$$
\text { H I S P T F }
$$

100

MTQVWI I DDDPSIRWVLEKALTQADI LVRSFADADSALRALGRE 2PGAVVTDLRMPGLDGLAFLREVQSRWPKLPVIVMTAHSDLDNAVAAFQSGAFE MORG I VWVDDDSS I RWVLERAI_AGAGLTCTTFENGAEVLEALASK'P PVLLLSDIRMPGMDGLALLKOIKORHPMLPVI IMTAHSDLDAAVSAYOOGAFD MQRG IAWIVDDDSS IRWVLERALTGAGLSCTTFESGNEVLDALTTK'?PDVLLSDIRMPGMDGLALLKQIKQRHPMLPVI IMTAHSDLDAAVSAYQQGAFD MQKGNVWVVDDDSS IRWVLERAI TREGMLCRAFEHANDVLKALNSE(2PDVLLSDIRMPDMDGLSLLKI IKEQYPTLPVI IMTAHSDLDAAVNAYQQGAPD MPAGS I LVADDDTAIRTVLNQALSRAGYEVRLTGNAATLWRWVSOG RGDLVITDVVMPDENAFDLLPRIKKMR PNLPVIVMSAQNTFMTATRPSERGAYE MTGAT I LVADDDAAIRTVLNQALSRAGYDVR ITSNAATLWRWIAAG| GDLVVTDVVMPDENAFDLLPR I KKAR PDLPVLVMSAQNTFMTAI KASEKGAYD MDGTVLVADDDRTIRTVLTQALTRAGCXVHATASLMTLMRWVEEGKGDLVISDVVMPDGNGLEALARIARERPGLPVIVI SAQNT IMTAIQAAEADAYD MTAT I LVADDDAAIRTVLNQALSRAGYDVRI TSNAATLWRWVSAGI'GDLVVTDVVMPDENAFDLLPRIKRARPDLPVLVMDAQMTFMTAI KASEKGAYD MSAAT I LVADDDRAID. VLTQALARIGHEVRTTGNASTLWRWVADG(GGDLI ITDVVMPDENGLDLI PRIKX IRPDLR I IVMSAQNTLI TAVKAAERGAFE L I P LPV M A

YLPKPFDMDEAVTLVQRALGSRAGPGAAGVEESDPAE . . . . . MIGI APAMQEVF . RAIGRLSRSQINVLITGESGSGKELVASALHRHSPRARGPFIA YLPKPFDIDEAVALVERAI SHTQEQQQPRNVQLNGP . . . . . TTD I I AY . PAMQDVF . . RI IGRLSRSS I SVLINGESGTGKELVAHALHRHSPRAKAPF IA YLPKPPDIDEAVALVDRAI SHYQEQQQPRNAPINSP . . . . TADI IGHAPAMQDVF . . RI I GRLSRSS I SVLINGESGTGKELVAHALHRHSPRAKAPFIA YLPKPFDIDETLALI IERA I THYREQKQPNNAEN ILQS . . . VSDMIGE APAMQEVY . . RI IGRLSRSS I SVLINGESGTGKELVAHALHRHSPRALAPF IA YLPKPFDLKELITIVGRALE PKERVSSPADDGEFDS . . . . . IPLVGE SPAMQEIY . . RVLAARLMQTDLTVMI SGESGTGKELVARALHDYGRRRNGPFVA YLPKPFDLTELIGI I GRALAEPRRR PSKLEDDSQDG . . . . . MPLVGR SAAMQE IY . . RVLARLMQTDLTLMITGESGTGKELVARALHDYGKRRNGPFVA YLPKPFDLPDLMKRAARALELTRRAQVVPKVIETSRPEGTDLPLVGF TAAMQAL YRLRLVARVMNADLPVMIMGESGTGKSLIAKAIHDFSDRRTLPFVV YLPKPFDLTELIAI I GRALSE PKRKPAKLDDDMQDG . . . . MPLVGR SAAMOE IY . . RVLARLMQTDLTLMITGESGTGKELVARALHDYGKRRNGPFVA

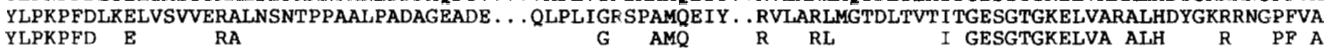
INTAA I PAELLESELFGHERGAFTGAVQTRQGRFEQASGGTLFLDE I GDMPAALQTRLIRVLSDGTFYRVGGHAPQRADVRVLAAATHQNLEAKVRDGS . F I.NMAA I PKDLI I SELLFGHEKGAFTGANT' IROGRFEQADGGTLFLDE I GDMPLDVQTRLLRVLADGQFYRVGGYAPVKVDVR I I AATHQNLELRVOEGK . F LNMAA I PKDLIESELFGHEKGAFTGANTVRQGRFEQADGGTLFLDEI GDMPLDVQTRLI.RVLAADGQFYRVGGYAPVKVDVRI IAATHQNLELRVQEGK . F LNMAA I PKDLI IESELFGHEKGAFTGASQVRQGRFEQANGGSLFLDE I JDMPLDIQTRLLRVLAEGQFYRVGGYAPVKVDVR I IAATHQDLEKRVNEGD . F VNMAAI PRDLIESELFGHERGAFTGAN'TRASGRFEQAEGGTLFLDEI JDMPMEAQ'TRLLRVLQQGEYTTVGGRTPIKTDVR IVAASNKDLRIL IQQGL . F INMAA I PRDLIESELPGHEKGARTGAOTRSTGRFEOAAGGLFTLDE I GDMPMDAOTRLLRVLOOGEYTTVGGRTPIRSDVR IVAATNKDLKOSINOGL. F AQAA . . DLLGAD . . . . . . . GPSLLARRQGRL . . . . . VVFDEV GDYDDETOGR IVRMLDALPDPP . . . . . . . . RIMATTQVDLGALMEAGRRF

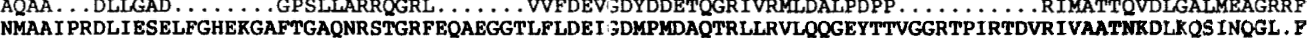
INMAAIPRDLIESELFGHERGAFTGAQNRSTGRFEQAEGGTLFLDEI IDMPMDAQTRLLRVLQOGEYTTVGGRTPIRTDVR IVAATNKDL.RQS INQGL . F

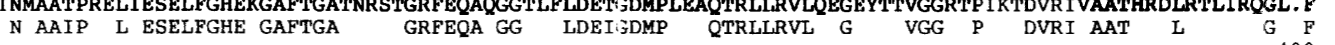
REDLYHRLNVIHIHLP PIRERREDI PRLAARHFLRRSAEQLDVERR I L SPERVAFMNW. HWPGNVROLENVCRWITVMAPTREVOVTDLPPEMAASPMSAM REDLFHRINVIRVHLPPLRERREDI PRLARHFLQVAARELGVEAKLIJPETEAALTRLAWPGNVRQLENTCRWLTVMAAGQEVLIQDLPGELFESTVAES REDLFHRINVIRVHLPPLRERRED I PRLARHFLQIAARELGVEAKQUIIPETEMALTRLAWPGNVRQLENTCRWLTVMAAGQEVLTQDLPSELFETAIPDN RED LY HRLNVIRIQLPPLRDRTEDI PSLARY FLQKTAKELGVETK SLHEQSLKTMYEYVWSGNVRQLENVCRWLTVMTASQE IMPODLPSE I RLADEKAK REDLFFRLNVVPLRVPPLRER IEDLPDLIRHFFSLAEKD. GLPPKKLIIAQALERLKQHRWPGNVRELENLARRLAALYP. QDVITASVIDGELAPPAVTS REDLYYRLNVVPLRLPPLRDRAEDI PDLVRHFVQQAEKE. GLDVKRFIVQEALELMKAHPWPGNVRELENLVRRLTALYP. QDVITREI IENELRSEI PDS QDLY YR LGGVTLAVPALRERVEDI PLLLAEHFLGRAERD. GLGMRAF SAEAMGLVRAYAWPGNVRQLENTVRRLVVT'ASEEE ITRTEVEFVLGNQPAVEP

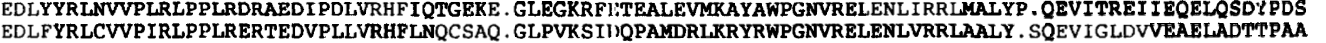
REDL RL V PPLR R ED P L RHF G G WPGNVR LEN R L

MPDPNTQD . WRLLLIGAVVRHVSRREEA . LLDKIQP . . . . . . . LFEK CLLEAALQHTRGHKQSAAHKLGWGRNTLTRKLRELGMAEDT T'SQMQPDS . WATLLAQWADRALRSGHQNLLSEAQP . . . . . . . E E EERTLLTTALRHTQGHKQEAARLLGWGRNTLTRKLKELGME PTQMLPDS . WATLLGQWADRALRSGHQNL.LSEAQP . . . . . . EMERTLLTTALRHTQGHKQEAARLLGWGRNTLTRKLKELGME

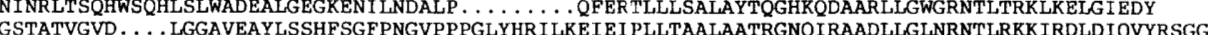
PI EKAAARSGSLSISQAVEENMRQY FASFGDALPPSGLYDRVLAEMEY PLI LAALTATRGNQI KAADLLGLNRNTLRKK IRELGVSVYRSLA LGAGGEGEK ... . . LSAS IARHLRR Y FDLHGGNL P P PGLYDR ILAEMEA PLIE IALDATGGNQAKCADLLG INRNTLRKKI TDLD IQVTRRRKLM PLDKMAVRTGSLTI SQAVEENMRDY FASFGDGLPPPGL YDRVLRELEY PLI LAALTATRGNQI KAADLLGLNRNTLRKKI RELGVSVYRSSR PS $\mathrm{P}$ E L AL T G AA LUG RNTL K L

Fig. 4 (a, b). For legend see facing page. 
limiting conditions (Table 2). In contrast, E. coli YMC10$\left(n t r C^{+}\right)(\mathrm{pH} / a c)$ cells had 150-fold greater levels of $\beta$ galactosidase activity. The presence of a cloned $K$. pneumoniae ntrC gene was able to partially complement the ntr C mutation, as E. coli ET8556(pHlac, pFB514) cells had 60 -fold greater levels of $\beta$-galactosidase activity than E'T8556(pHlac) cells (Table 2). These results formed the rationale behind the strategy to isolate the $T$. ferrooxidans $n \operatorname{tr} C$ gene by activation of expression of the $T$. ferrooxidans nif $\mathrm{H}-\mathrm{lac} \mathrm{Z}$ fusion.

The T. ferrooxidans cosmid bank was transduced into the E. coli ET8556 ntrC mutant containing the T. ferrooxidans nif $\mathrm{H}-\mathrm{lac} Z$ fusion. After growth on GMM low-nitrogen plates and flooding with ONPG, six positive clones were identified and purified. Cosmid DNA was extracted from cultures of each clone and retransformed into the same strain as used to screen the bank. Each clone retested positive for $\beta$-galactosidase activity. The cosmids had several restriction fragments in common and appeared to contain overlapping pieces of the same region of the $T$. ferrooxidans genome. One cosmid clone, pT101, was chosen for further study.

\section{Localization of the $\boldsymbol{T}$. ferrooxidans ntrC gene}

A $13.5 \mathrm{~kb}$ HindIII fragment of cosmid pT101, which was subcloned into the vector $\mathrm{p} E c o \mathrm{R} 252$ to give $\mathrm{pT} 110$, was still able to activate $T$. ferrooxidans nif $H$-lac $Z$ expression (Fig. 2). A restriction map of pT110 was constructed and $5.2 \mathrm{~kb}$ HindIII-KpnI and $4.47 \mathrm{~kb}$ EcoRI-HindIII fragments (pT120 and pT130 respectively) were subcloned into the vector $\mathrm{pBluescript} \mathrm{SK}$. Both fragments retained the ability to activate the $\mathrm{pH}$ lac fusion and the nucleotide sequence of the pT130 insert was determined from both strands.

\section{Nucleotide sequence of the $T$. ferrooxidans $n$ trBC genes}

Analysis of the sequence data revealed three ORFs (Figs 2 and 3), each starting with an ATG and each preceded by a short sequence that could serve as a ribosome-binding site. The first and second ORFs coded for proteins with calculated $M_{\mathrm{r}}$ values of 40278 and 51894 respectively. The $n t r B C$ genes overlapped slightly, with the TGA stop codon of $n t r B$ providing part of the ATG start codon of $n \operatorname{tr} C$. Using the TFASTA subroutine of the GCG package, the predicted amino acid sequence of the first ORF clearly aligned with the $\mathrm{NtrB}$ sequences and the amino acid sequence of the second ORF with the $\mathrm{NtrC}$ sequences of the GenBank (release 76) database (Fig. 4a, b). This indicated that the first ORF encoded the $T$. ferrooxidans $\mathrm{NtrB}$ protein and the second ORF the $\mathrm{NtrC}$ protein. The amino acid sequences of $T$. ferrooxians $\mathrm{NtrB}$ and $\mathrm{NtrC}$ proteins were most similar to those of the $\gamma$ proteobacteria. The $T$. ferrooxidans $\mathrm{NtrB}$ protein had 39 to $40 \%$ sequence identity with the $\mathrm{NtrB}$ proteins of $E$. coli, $K$. pneumoniae, Proteus vulgaris and Vibrio alginolyticus, while the $\mathrm{NtrC}$ protein had 63, 61 and 59\% sequence identity to the $\mathrm{NtrC}$ proteins of $K$. pneumoniae, $E$. coli and $P$. vulgaris respectively.

A putative promoter sequence, -CTGGTGCGCTTTTTGCTT-, which has the conserved GG and GC bases, the correct spacing and an 8 out of 11 bp match with the consensus sequence (CTGGCAC-N5-TTGCA) of $\sigma^{54}$ dependent promoters, was found immediately upstream of the $n \operatorname{trB}$ gene (Fig. 3). This putative promoter had a poly $(\mathrm{T})$ tract in position -14 to -18 , which is thought to facilitate high-affinity binding between the promoter and $\sigma^{54}$ (Buck \& Cannon, 1992). At least two potential NtrC-binding sites were located upstream of the proposed $n t r B$ translation start (Fig. 3). One site, approximately 190 bp upstream of $n \operatorname{tr} B$, had a one base pair mismatch to the conserved sequences of a -TGCACC-N - -TGGTGCAconsensus NtrC-binding site (Ames Ferro-Luzzi \& Nikaido, 1985). There were several other sequences which matched one or other, but not both of the elements of a consensus NtrC-binding site.

A third ORF which could encode a protein of calculated $M_{\mathrm{r}} 35106$ was located immediately downstream of the $n \operatorname{tr} C$ gene. A potential ribosome-binding site, GGGG, was situated 5 bp upstream of the ORF. Codon preference analysis with a codon usage table derived from previously sequenced T. ferrooxidans genes (Rawlings et al., 1991) indicated that this ORF was likely to be protein-encoding. A search of the GenBank/EMBL database (release 76) for proteins with homology to this ORF using the predicted amino acid of the ORF and the BLASTNCBI subroutine (National Center for Biotechnology Information, National Institutes of Health, New Bethesda, USA) failed to indicate any similarity to the translated products of the deposited DNA sequences or proteins.

\section{Analysis of polypeptide synthesis}

An E. coli-derived in vitro transcription-translation system was used to identify polypeptides produced from the $T$. ferrooxidans clones (Fig. 5). A comparison between the proteins produced by the vector $\mathrm{pE}$ EcoR252 (lane 2) and clones pT120 and pT130 (lanes 3 and 4 respectively)

Fig. 4. Comparison of the amino acid sequences of (a) the T. ferrooxidans (Tf) NtrB protein and (b) the NtrC protein with those of other organisms. Ec, E. coli (Miranda-Rios et al., 1987); Kp, K. pneumoniae (MacFarlane \& Merrick, 1985; Buikema et al., 1985); Va, Vibrio alginolyticus (Maharaj et al., 1989); Pv, Proteus vulgaris (Steglitz-Mörsdorf et al., 1993); Bp, Bradyrhizobium parasponia (Nixon et al., 1986); Rc, Rhodobacter capsulatus (Jones \& Haselkorn, 1989); Ab, Azospirillum brasilense (Liang et al., 1993); At, Agrobacterium tumefaciens (Wardhan et al., 1989); Rm, Rhizobium meliloti (Szeto et al., 1987). Consensus amino acids are listed below the sequence alignments. Only amino acids which were identically conserved in seven out of eight NtrB proteins and eight out of nine NtrC sequences compared have been included in the consensus. 


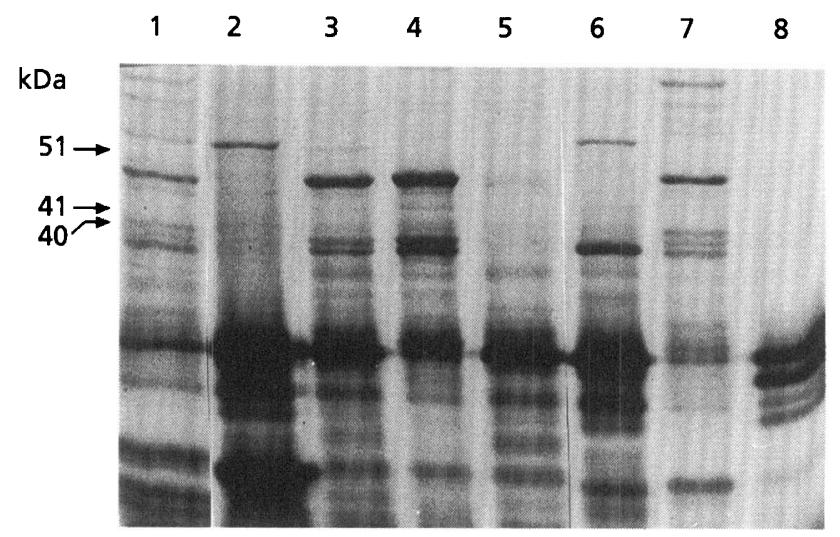

Fig. 5. SDS-PAGE analysis of proteins expressed from pT101 and subclones in an $E$. coli-derived in vitro transcription-translation system. Lanes: 1, pT101; 2, pEcoR252; 3, pT120; 4, pT130; 5 , pT127; 6, pT128; 7, pT110; 8, pBluescript SK. Maps of all constructs except cosmid clone pT101 are shown in Fig. 2. The 51,41 and $40 \mathrm{kDa}$ bands indicated by means of arrows are the products of $n t r C$, its cleavage product and $n t r B$ respectively.

indicated that three polypeptides, of $51 \mathrm{kDa}, 41 \mathrm{kDa}$ and $40 \mathrm{kDa}$, were synthesized from both clones. The $51 \mathrm{kDa}$ band corresponded closely to the predicted $M_{\mathrm{r}}$ of 51894 for NtrC. When DNA encoding NtrC and the third ORF was deleted but the DNA encoding $\mathrm{NtrB}$ remained, only the $40 \mathrm{kDa}$ band was synthesized (pT128; Fig. 5, lane 6). This identified the $40 \mathrm{kDa}$ band as $\mathrm{NtrB}$ (predicted $M_{\mathrm{r}}$ 40278). When only the third ORF was deleted (construct p'T132, Fig. 2), all three of the proteins were still produced (results not shown). This indicated that the $41 \mathrm{kDa}$ protein was a breakdown product of the $51 \mathrm{kDa} \mathrm{NtrC}$ protein. No polypeptide corresponding to the predicted size of the product of the third ORF (35 kDa) was detected. It is possible that a promoter which is required for expression of this third ORF but which is not recognized in the $E$. coli in vitro transcription-translation system is located in the region between the $n \operatorname{tr} C$ gene and the third ORF. When the ClaI-Pst I fragment of pT130 was deleted and only the ClaI-HindIII fragment containing $\mathrm{NtrC}$ and the third ORF remained, no proteins were detected (pT127; Fig. 5, lane 5).

Besides NtrB, NtrC, and the $41 \mathrm{kDa}$ protein, an additional polypeptide of $42 \mathrm{kDa}$ was produced from $\mathrm{pT} 110$ in the E. coli-derived transcription-translation system (Fig. 5, lane 7). All four proteins were also produced from p T101, the cosmid clone that was the source of all other subclones used in this study (Fig. 5, lane 1). This unidentified protein appears to be synthesized from the region of pT110 and pT101 that lies upstream of the ntrB gene.

\section{The $T$. ferrooxidans $n \operatorname{tr} B C$ genes and the glnA gene are not linked}

No $n \operatorname{tr} B$ gene had been located in the 350 bp region downstream of the previously sequenced $T$. ferrooxidans $g \ln A$ gene (Rawlings et al., 1987). Likewise no portion of the $\operatorname{gn} A$ gene was found in the approximately $900 \mathrm{bp}$ upstream of the $n \operatorname{tr} B$ gene (Fig. 3). In order to investigate (a)

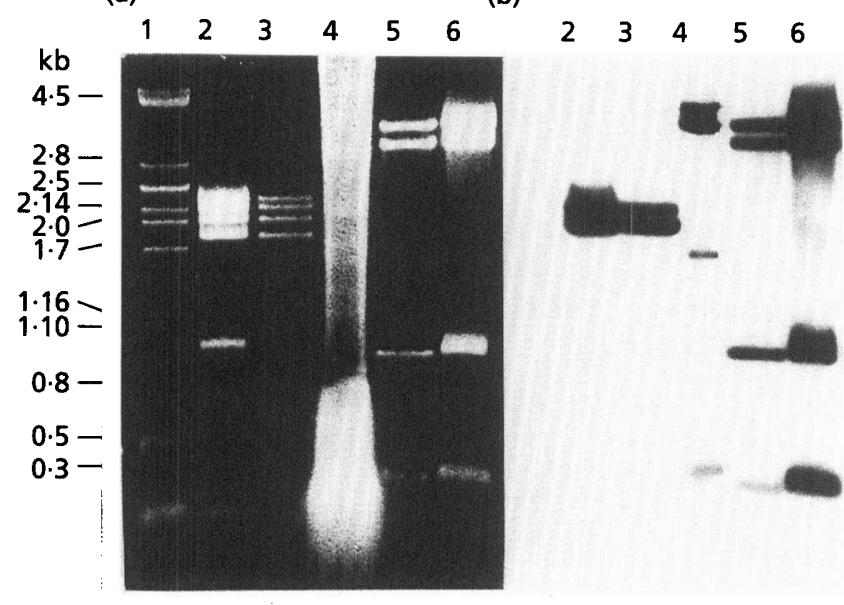

Fig. 6. Hybridization of labelled pT120 DNA to $T$. ferrooxidans chromosomal DNA and plasmid digests. (a) Photograph of an agarose gel containing Pstl digests of (in lanes) $1, \lambda$ DNA; 2 , $500 \mathrm{ng}$ of pMEB100; 3, $100 \mathrm{ng}$ of PMEB $100 ; 4,15 \mathrm{mg}$ of $T$. ferrooxidans chromosomal DNA; $5,100 \mathrm{ng}$ of pT120; 6, $500 \mathrm{ng}$ pT120. (b) Autoradiograph of panel (a).

further the lack of linkage between the $T$. ferrooxidans $g \ln A$ and $n \operatorname{tr} B C$ genes, Southern hybridization experiments were carried out. Chromosomal DNA isolated from T. ferrooxidans ATCC 33020 was digested with Pst I and hybridized to labelled pT120. The $3.6 \mathrm{~kb}$ and $300 \mathrm{bp}$ fragments internal to the pT120 insert hybridized to $T$. ferrooxidans chromosomal fragments of the same size (Fig. 6 , lanes 4 and 5). The $300 \mathrm{bp}$ fragment was slightly retarded due to the overloading of $T$. ferooxidans chromosomal DNA required to give a signal from the small fragment. Analysis of the sequence data indicated that the $n \operatorname{tr} B C$ genes were located completely within the $3.6 \mathrm{~kb}$ Pst I fragment. In contrast, the $T$. ferrooxidans $g \ln A$ gene is located on a $2.35 \mathrm{~kb}$ Pst I chromosomal fragment (Rawlings et al., 1987), the uppermost band of the $g \ln A$ pMEB100 clone (Fig. 6a, lane 3). No T. ferrooxidans chromosomal fragment of this size hybridized to the p'T120 probe. The two fragments of pMEB100 that hybridized to the pT120 probe were the $2 \cdot 1$ and $1.75 \mathrm{~kb}$ fragments which contained pEcoR251 vector DNA sequences that are homologous to the pBluescript SK vector of pT120. Furthermore, Pst I restriction digests of pT110 did not indicate the presence of a $2.35 \mathrm{~kb}$ band which would have been predicted had the $\operatorname{gn} A$ gene been located within the $6 \mathrm{~kb}$ region upstream of the $n \operatorname{tr} B$ genes (data not shown).

\section{Expression of the $T$. ferrooxidans nifH-lacZ fusion in the presence of the cloned ntrBC genes}

The effect of the presence of the cloned T. ferrooxidans $n t r B$ and $n \operatorname{tr} C$ genes on expression of the $T$. ferrooxidans nif $H-l a c Z$ fusion was investigated. $\beta$-Galactosidase assays of $E$. coli cells grown in liquid culture were carried out in nitrogen-limiting and nitrogen-rich media. Low levels of $\beta$-galactosidase activity were obtained from ET8556( $\mathrm{pH}$ lac20, $\mathrm{pHC} 79$ ) ntr $C$ control cells grown with high or 
low levels of nitrogen (Table 2). ET8556(pHlac20, pT101) cells, which contained the $T$. ferrooxidans ntr $B C$ genes as a cosmid insert in the vector $\mathrm{pHC79}$, produced levels of $\beta$ galactosidase activity that were threefold greater than control levels when grown under nitrogen-limiting conditions. In nitrogen-rich media there was a twofold repression of $\beta$-galactosidase activity compared with nitrogen-poor media. ET8556(pHlac20, pT130) cells, which contained the $T$. ferrooxidans ntr $B C$ genes on the high copy pBluescript SK vector, had approximately twofold higher $\beta$-galactosidase levels compared with ET8556(pHlac20, pT101) cosmid-containing cells when grown in nitrogen-poor media. The cloned $K$. pneumoniae $n \operatorname{tr} B C$ genes on $\mathrm{pK} 70$ were capable of inducing expression from the $T$. ferrooxidans nif $H$-lac $Z$ fusion to the same level as the cloned $T$. ferrooxidans $n$ tr $B C$ genes (Table 2, rows 6 and 8 ). The chromosomal E. coli ntrBC genes present in YMC10 were, however, far more efficient at inducing expression from the $T$. ferrooxidans nif $H-l a c Z$ fusion than the cloned genes. In high-nitrogen growth conditions $\beta$ galactosidase activity was repressed to approximately equal levels irrespective of the source of the $n t r B C$ genes. Activation of the $T$. ferrooxidans nif $H$-lac $Z$ fusion was also examined in the E. coli ntrBC deletion strain ET8051. ET8051(pHlac20, pT130) produced fourfold greater levels of $\beta$-galactosidase than the ET8051(pHlac20) control when grown under low-nitrogen conditions. The $\beta$ galactosidase activity of ET8051(pHlac20, pT130) was lowered in high-nitrogen medium, but not to the extent that was observed in YMC10(pHlac20, pHC79). A similar trend was observed for ET8051(pHlac20, p804) containing cloned $E$. coli ntrBC genes, although its $\beta$ galactosidase levels were approximately twofold higher than those of ET8051(pHlac20, pT130), which contained the $T$. ferrooxidans ntr $B C$ genes.

\section{DISCUSSION}

The $K$. pneumoniae nifH promoter is activated by NifA, but not activated by $\mathrm{NtrC}-\mathrm{PO}_{4}$ in $K$. pneumoniae (Merrick, 1983). This is consistent with the two-tiered model of regulation of the $K$. pneumoniae nif genes in which $\mathrm{NtrC}$ is responsible for regulation of expression of nifL $A$ at the first level only. The unresponsiveness of the $K$. pneumoniae nifH promoter to $\mathrm{NtrC}-\mathrm{PO}_{4}$ is thought to prevent expression of nif genes under inappropriate circumstances, such as in aerobic nitrogen-limiting conditions. Although the $K$. pneumoniae nif $H$ promoter was also not activated in an E. coli background (Merrick, 1983), the expression of nif genes cloned from other bacteria may not necessarily mimic that in the original organism. The $T$. ferrooxidans nifH regulatory region contains two canonical NifA upstream activator sequences (Pretorius et al., 1987), which indicates that a NifA-like protein is likely to function as activator of the nif $H$ gene in $T$. ferrooxidans. We set out to isolate the T. ferrooxidans nif $A$ gene by screening for transformants in which expression of a $T$. ferrooxidans nif $\mathrm{H}-\mathrm{lac} Z$ fusion had been activated. Because of the similarity of the $T$. ferrooxidans nif $H$ promoter sequence with the Rbizobium meliloti nifH promoter and certain $K$. pneumoniae nifH mutant promoters (from which transcription may be mediated by NtrC-PO4; Fig. 1), we tested whether transcription of the $T$. ferrooxidans nif $\mathrm{H}_{-}$ lac $Z$ fusion could also be $\mathrm{NtrC}$-mediated in E. coli. Since $\mathrm{NtrC}$-mediated activation of the $T$. ferrooxidans nifH-lac $Z$ promoter did occur, we thought it possible that either the $T$. ferrooxidans nif $A$ or $n \operatorname{tr} C$ genes or both could be isolated by screening for $\beta$-galactosidase production in an $E$. coli ntrC mutant. Some screening experiments were carried out under anaerobic conditions at $30^{\circ} \mathrm{C}$ (Forma Scientific anaerobic glove box, $\mathrm{N}_{2}: \mathrm{CO}_{2}: \mathrm{H}_{2}$ ratio $85: 15: 5)$ to allow for the possibility that the expression of nif $A$, or the activity of NifA from $T$. ferrooxidans, might be affected by oxygen or temperature. The $T$. ferrooxidans $n \operatorname{tr} C$ gene was reisolated on several occasions during the course of both the aerobic and anaerobic screenings, but to date the $T$. ferrooxidans nif $A$ gene has not been isolated (unpublished data).

Activation of the T. ferrooxidans nif $\mathrm{H}$ promoter by $\mathrm{NtrC}$ in $E$. coli may have been due to sequences upstream of the $T$. ferrooxidans nif $\mathrm{H}$ gene which resemble $\mathrm{NtrC}$-binding sites. Although no complete $\mathrm{NtrC}$-binding sites were apparent, examination of the nucleotide sequence upstream of the T. ferrooxidans nif $\mathrm{H}$ gene (Pretorius $e t$ al., 1987) revealed sequences with identity to one or other half of a $\mathrm{NtrC}$ consensus binding site. Reitzer et al. (1989) have provided evidence that $\mathrm{NtrC}-\mathrm{PO}_{4}$ can bind weakly to a partial NtrC-binding site. Alternatively, positions of certain bases within the $T$. ferrooxidans nifH promoter (Fig. 1) could affect the stability of the closed promoter complex compared to that of the $K$. pneumoniae nifH promoter and allow the activation by $\mathrm{NtrC}-\mathrm{PO}_{4}$ from solution in the absence of a specific NtrC-binding site. Buck \& Cannon (1989) demonstrated that transcription from a K. pneumoniae nif $H$ promoter which contained transition mutations in the -15 to -17 region could be increased due to activation from solution by a form of NifA protein which was unable to bind to an upstream activator sequence. Whatever the method of activation of the T. ferrooxidans nif $H$ gene in the $E$. coli system used, it provided a convenient colorimetric plate screening method for identifying the $T$. ferrooxidans $n \operatorname{tr} B C$ genes.

We developed the above method because we were unable to isolate the $T$. ferrooxidans ntrBC genes by using their ability to complement E. coli ntr $C$ mutants for growth on minimal medium plus arginine. Having cloned and confirmed the presence and expression of the $T$. ferrooxidans ntr BC genes in E. coli, we again tested whether the cloned genes were able to complement the E. coli ntrC mutant ET8556 for growth on minimal medium plus arginine. No growth was obtained with ET8556(pT101) or ET8556(pT110). ET8556(pT130) cells in which the $n t r B C$ genes were present on a high-copy-number pBluescript SK vector did form very small colonies after at least $72 \mathrm{~h}$ of incubation at $30^{\circ} \mathrm{C}$.

The results of the complementation experiments showed that the $T$. ferrooxidans $n \operatorname{tr} B$ and $n \operatorname{tr} C$ genes together activated NtrC-directed expression of the $T$. ferrooxidans nif $\mathrm{H}$-lac $\mathrm{Z}$ fusion to produce $\beta$-galactosidase levels clearly above basal levels. Regulation of this expression in response to nitrogen was, however, not as clear as for the 
YMC10 ntrBC $C^{+}$control. The lack of efficient regulation of the $T$. ferrooxidans nif $H-l a c Z$ fusion by cloned $T$. ferrooxidans ntrBC genes compared to the $E$. coli $n \operatorname{tr} B C$ chromosomal equivalent is probably due to the cloned $n t r B C$ genes being carried on a multicopy plasmid. Overexpression would result in concentrations of both proteins bearing no relation to the normal stoichiometry within the cell, resulting in poor nitrogen regulation.

Unlike those of the enteric bacteria and $A$. vinelandii, the $T$. ferrooxidans ntrBC genes are not located immediately downstream of the $g \ln A$ gene. It is interesting to note the distribution of the $g \ln A L G$ or $g \ln A / n \operatorname{tr} B C$ operon structure amongst bacteria in which this has been investigated. Bacteria have been divided into a number of phylogenetic divisions on the basis of $16 \mathrm{~S}$ rRNA sequence data (Woese, 1987). All the bacteria for which ntrBC sequence information is available belong to the division proteobacteria (previously called purple bacteria). The proteobacteria have again been divided into four subdivisions, $\alpha, \beta, \gamma$ and $\delta$. E. coli, K. pneumoniae, Proteus vulgaris, Vibrio alginolyticus and $A$. vinelandii all belong to the $\gamma$ subdivision (Woese, 1987). In each of these bacteria, the $n \operatorname{tr} B$ and $n \operatorname{tr} C$ genes are located downstream of the $g \ln A$ gene. $T$. ferrooxidans has been placed in the $\beta$ subdivision of proteobacteria (Lane et al., 1991) whereas Rhizobium meliloti and Rhodobacter capsulatus are members of the $\alpha$ subdivision. In these bacteria the $n \operatorname{tr} B C$ genes (or their R. capsulatus homologues, nifR2 and nifR1) do not appear to be downstream of the gln $A$ gene. Bradyrbizobium parasponia, Azospirillum brasilense and Agrobacterium tumefaciens are also members of the $\alpha$ subdivision but the physical proximity of the $B$. parasponia and $A$. brasilense $n \operatorname{tr} B C$ genes and the $A$. tumefaciens ntr $C$ gene to their $g \ln A$ genes has not been reported. As other $n \operatorname{tr} B C$ genes are studied, it will be interesting to find out whether the linkage of $g \ln A$ to the $n \operatorname{tr} B C$ genes is a characteristic of members of the $\gamma$ proteobacteria only, or whether this linkage also applies to any other groups of bacteria.

\section{ACKNOWLEDGEMENTS}

We thank F. Ausubel for providing plasmid pFB514, R. Haselkorn for $\mathrm{p} 804$ and strain ET8051, P. Janssen for $\mathrm{pEcoR} 252$ and M. Merrick for strain ET8556. We also wish to thank the Foundation for Research Development and Gencor Process Laboratories for their financial support.

\section{REFERENCES}

Ames Ferro-Luzzi, G. \& Nikaido, K. (1985). Nitrogen regulation in Salmonella typhimurium. Identification of an $n t r C$ protein binding site and definition of a consensus binding sequence. EMBO $\mathrm{J} \mathrm{4}$, 539-547.

van Aswegen, P. C., Godfrey, M. W., Miller, D. M. \& Haines, A. K. (1991). Developments and innovations in bacterial oxidation of refractory ores. Miner Metallurg Processing 8, 188-192.

Backman, K., Chen, Y.-M. \& Magasanik, B. (1981). Physical and genetic characterization of the $g \ln A-g \ln G$ region of the Escherichia coli chromosome. Proc Natl Acad Sci US A 78, 3743-3747.

Barros, M. E., Rawlings, D. E. \& Woods, D. R. (1985). Cloning and expression of the Thiobacillus ferrooxidans glutamine synthetase gene in Escberichia coli. J Bacteriol 164, 1386-1389.
Benyon, J., Cannon, W., Buchanan-Wollaston, V. \& Cannon, F. (1983). The nif promoters of Klebsiella pneumoniae have a characteristic primary structure. Cell 34, 665-671.

Berger, D. K., Woods, D. R. \& Rawlings, D. E. (1990). Complementation of Escherichia coli $\sigma^{54}(\mathrm{NtrA})$-dependent formate hydrogenlyase activity by a cloned Thiobacillus ferrooxidans ntr $A$ gene. $J$ Bacteriol 172, 4399-4406.

Buck, M. \& Cannon, W. (1989). Mutations in the RNA polymerase recognition sequence of the Klebsiella pneumoniae nifH promoter permitting transcriptional activation in the absence of NifA binding to upstream activator sequences. Nucleic Acids Res 17, 2597-2612.

Buck, M. \& Cannon, W. (1992). Specific binding of the transcription factor sigma-54 to promoter DNA. Nature 358, 422-424.

Buikema, W. J., Szeto, W. W., Lemley, P. V., Orme-Johnson, W. H. \& Ausubel, F. M. (1985). Nitrogen fixation specific regulatory genes of Klebsiella pneumoniae and Rbizobium meliloti share homology with the general nitrogen regulatory gene $n \operatorname{tr} C$ of Klebsiella pneumoniae. Nucleic Acids Res 13, 4539-4555.

De Bruijn, F. J. \& Ausubel, F. M. (1981). The cloning and transposon $T n 5$ mutagenesis of the $g \ln A$ region of Klebsiella pneumoniae: identification of $g \ln \mathrm{R}$, a gene involved in the regulation of the nif and but operons. Mol \& Gen Genetics 183, 289-297.

Drummond, M. H., Clements, J., Merrick, M. \& Dixon, R. (1983). Positive control and autogenous regulation of the nif $\mathrm{L} A$ promoter in Klebsiella pneumoniae. Nature 301, 302-307.

Drummond, M. H., Contreras, A. \& Mitchenall, L. A. (1990). The function of isolated domains and chimeric proteins constructed from the transcriptional activators NifA and $\mathrm{NtrC}$ of Klebsiella pneumoniae. Mol Microbiol 4, 29-37.

Hohn, B. \& Collins, J. (1980). A small cosmid for efficient cloning of large DNA fragments. Gene 11, 291-298.

Jones, R. \& Haselkorn, R. (1989). The DNA sequence of the Rhodobacter capsulatus ntr $A, n \operatorname{tr} B$ and $n \operatorname{tr} C$ gene analogues for nitrogen fixation. Mol \& Gen Genet 215, 507-516.

Keener, J. \& Kustu, S. (1988). Protein kinase and phosphatase activities of nitrogen regulator proteins $\mathrm{NtrB}$ and $\mathrm{NtrC}$ of enteric bacteria: roles of the conserved amino terminal domain of $\mathrm{NtrC}$. Proc Natl Acad Sci US A 85, 4976-4980.

Lane, D. J., Harrison, A. P., Jr, Stahl, D., Pace, B., Giovannoni, S. J., Olson, G. J. \& Pace, N. R. (1991). Evolutionary relationships among sulfur- and iron-oxidizing bacteria. J Bacteriol 174, 269-278.

Liang, Y. Y., Arsene, F. \& Elmerich, C. (1993). Characterization of the $n t r B C$ genes of Azospirillum brasilense Sp7: their involvement in the regulation of nitrogenase synthesis and activity. Mol \& Gen Genet 240, 188-196.

Lundgren, D. G. \& Silver, M. (1980). Ore leaching by bacteria. Annu Rev Microbiol 34, 263-283.

Maharaj, R., Rumbak, E., Jones, W. A., Robb, S. M., Robb, F. T. \& Woods, D. R. (1989). Nucleotide sequence of the Vibrio alginolyticus gln A region. Arch Microbiol 152, 542-549.

MacFarlane, S. A. \& Merrick, M. (1985). The nucleotide sequence of the nitrogen regulation gene $n t r B$ and the gln $A-n t r B C$ intergenic region of Klebsiella pneumoniae. Nucleic Acids Res 13, 7591-7606.

Merrick, M. (1983). Nitrogen control of the nif regulon in Klebsiella pneumoniae: involvement of the $n \operatorname{tr} A$ gene and analogies between $n \operatorname{tr} C$ and nif $A$. EMBO J 2, 39-44.

Miranda-Rios, J., Sanchez-Pescador, R., Urdea, M. \& Covarrubias, A. A. (1987). The complete nucleotide sequence of the $g \ln A L G$ operon of Escherichia coli K12. Nucleic Acids Res 15, 2757-2770.

Ninfa, A. J. \& Magasanik, B. (1986). Covalent modification of the $g \ln G$ product, $\mathrm{NR}_{\mathrm{I}}$, by the $g \ln L$ product, $\mathrm{NR}_{\mathrm{II}}$, regulates tran- 
scription of the gln ALG operon in Eschericbia coli. Proc Natl Acad Sci US. A 83, 5909-5913.

Nixon, T. B., Ronson, C. W. \& Ausubel, F. M. (1986). Twocomponent regulatory systems responsive to environmental stimuli share strongly conserved domains with the nitrogen regulatory genes $n t r B$ and $n t r C$. Proc Natl Acad Sci US A 83, 7850-7854.

Ow, D. \& Ausubel, F. M. (1983). Regulation of nitrogen metabolism genes by the nif $A$ gene product in Klebsiella pneumoniae. Nature 301, $307-313$

Ow, D., Xiong, Y., Gu, Q. \& Shen, S. C. (1985). Mutational analysis of the Klebsiella pneumoniae nitrogenase promoters: sequences essential for positive control by $n$ if $A$ and $n \operatorname{tr} C(g \ln G)$ products. $J$ Bacteriol 161, 868-874.

Pahel, G. \& Tyler, B. (1979). A new gln $A$-linked regulatory gene for glutamine synthetase in Escherichia coli. Proc Natl Acad Sci US A 76, 4544-4548.

Popham, D. L., Szeto, D., Keener, J. \& Kustu, S. (1989). Function of a bacterial activator protein that binds to transcriptional enhancers. Science 243, 629-635.

Pretorius, I.-M., Rawlings, D. E., O'Neill, E. G., Jones, W. A., Kirby, R. \& Woods, D. R. (1987). Nucleotide sequence of the gene encoding the nitrogenase iron protein of Tbiobacillus ferrooxidans. $J$ Bacteriol 169, 367-370.

Rawlings, D. E. (1988). Sequence and structural analysis of the $\alpha$ and $\beta$-dinitrogenase subunits of Thiobacillus ferrooxidans. Gene 69 , $337-343$.

Rawlings, D. E., Jones, W. A., O'Neill, E. G. \& Woods, D. R. (1987). Nucleotide sequence of the glutamine synthetase gene and its controlling region from the acidophilic autotroph Tbiobacillus ferrooxidans. Gene 53, 211-217.

Rawlings, D. E., Woods, D. R. \& Mjoli, N. P. (1991). The cloning and structure of genes from the autotrophic biomining bacterium Thiobacillus ferrooxidans. In Advances in Gene Tecbnology, vol. 2, pp. 215- 237. Edited by P. J. Greenaway. London: JAI Press.

Ray, L., Claveriemartin, F., Weglenski, P. \& Magasanik, B. (1990). Role of the promoter in activation of transcription by nitrogen regulator I phosphate in Escherichia coli. J Bacteriol 172, 818-823.

Reitzer, L. J. \& Magasanik, B. (1985). Expression of $g \ln A$ in
Escherichia coli is regulated at tandem promoters. Proc Natl Acad Sci US A 82, 1979-1983.

Reitzer, L. J., Movsas, B. \& Magasanik, B. (1989). Activation of $g \ln A$ transcription by nitrogen regulator $\mathrm{I}\left(\mathrm{NR}_{\mathrm{I}}\right)$-phosphate in Escherichia coli: evidence for a long range physical interaction between $\mathrm{NR}_{\mathrm{I}}$-phosphate and RNA polymerase. $J$ Bacteriol 171, $5512-5522$.

Sambrook, J., Fritsch, E. F. \& Maniatis, T. (1989). Molecular Cloning: a Laboratory Manual, 2nd edn. Cold Spring Harbor, NY: Cold Spring Harbor Laboratory.

Sanders, D. A., Gillece-Castro, B. L., Burlinghame, A. L. \& Koshland, D. E., Jr (1992). Phosphorylation site of NtrC, a protein phosphatase whose covalent intermediate activates transcription. $J$ Bacteriol 174, 5117-5122.

Steglitz-Mörsdorf, U., Mörsdorf, G. \& Kaltwasser, H. (1993). Cloning, heterologous expression, and sequencing of the Proteus vulgaris gln AntrBC operon and implications of nitrogen control on heterologous urease expression. FEMS Microbiol Lett 106, 157-164.

Sundaresan, V., Jones, J. D. G., OW, D. W. \& Ausubel, F. M. (1983). Klebsiella pneumoniae nif $A$ product activates the Rhizobium meliloti nitrogenase promoter. Nature 301, 728-732.

Szeto, W. W., Nixon, B. T., Ronson, C. W. \& Ausubel, F. M. (1987). Identification and characterization of the Rbizobium meliloti ntrC gene: R. meliloti has separate regulatory pathways for activation of nitrogen fixation genes in free-living and symbiotic cells. J Bacteriol 169, 1423-1432.

Toukdarian, A. \& Kennedy, C. (1986). Regulation of nitrogen metabolism in Azotobacter vinelandii: isolation of $n \operatorname{tr}$ and $g \ln A$ genes and construction of $n t r$ mutants. EMBO J 5, 399-407.

Tuli, R., Fisher, R. \& Haselkorn, R. (1982). The ntr genes of Escherichia coli activate the but and nif operons of Klebsiella pneumoniae. Gene 19, 109-116.

Wardhan, H., McPherson, M. J. \& Sastry, G. R. K. (1989). Indentification, cloning, and sequence analysis of the nitrogen regulation gene ntrC of Agrobacterium tumefaciens C58. Mol PlantMicrobe Interact 2, 241-248.

Woese, C. R. (1987). Bacterial evolution. Microbiol Rev 51, 221-271.

Received 4 March 1994; revised 23 May 1994; accepted 24 May 1994. 